\title{
A No-Sweat Strategy for Graphene-Macrocycle Co-assembled Electrocatalyst Towards Oxygen Reduction and Ambient Ammonia Synthesis
}

Ashmita Biswas, Subhajit Sarkar, Manisha Das, Navpreet Kamboj and Ramendra Sundar Dey*

Institute of Nano Science and Technology, Mohali-160062, Punjab, India.

Email: rsdey@inst.ac.in 


\section{Instrumentation}

The surface morphology, phase identification, crystallinity, elemental composition as well as the atomic mass $\%$ of the elements constituting the prepared catalyst sample were investigated using a number of instrumental techniques. Scanning Electron Microscopy (SEM) was executed by SEM Jeol JSMIT300 equipped with a Bruker XFlash 6130 Energy Dispersive X-ray Spectroscopy (EDS). To obtain an even more perceivable and interpretive surface image, Transmission Electron Microscopy (TEM) analysis were carried out on a JEM2100 instrument with a LaB6 filament suitable for High-Resolution TEM (HRTEM) studies. The sample was mounted on a holey carbon 400-mesh copper grid. X-ray Diffraction (XRD) study was implemented on a Bruker D8 Advances instrument using $\mathrm{Cu}-\mathrm{K} \alpha(\lambda=$ $1.5406 \AA$ ) radiation in the $2 \theta$ range of $10^{\circ}$ to $80^{\circ}$ with an acceleration voltage of $40 \mathrm{kV}$. Raman Spectroscopy was accomplished on a WITEC Focus Innovations Alpha-300 Raman confocal microscope at a laser wavelength of $532 \mathrm{~nm}$. X-ray photoelectron spectroscopy (XPS) was performed on a KAlpha plus XPS system by ThermoFisher Scientific instruments in an ultrahigh vacuum chamber (7X10-9 torr) using Al-Ka radiation (1486.6 eV). UV-vis characterizations were performed in UV-vis-NIR (Cary 5000 UV-vis-NIR) spectrophotometer that has the ability to measure $300-2800 \mathrm{~nm}$ by a Pb Smart NIR detector. For testing the non-contamination of nitrogen gas used during nitrogen reduction reaction with other nitrogenous impurities, Gas chromatography experiment were performed with the help of PerkinElmer, Arnel Engineered Solutions, Clarus 680 GC.

\section{Calculation of surface coverage by electro-active material and weight $\%$ of FePc utilized in the reduction processes}

The surface coverage of electro-active material was calculated by means of the following equation-12: 


$$
\tau=\frac{Q}{n \times F \times A}
$$

where $\tau=$ surface coverage of G-FePc, $\mathrm{Q}=$ accumulated charge; $\mathrm{n}=$ number of electrons per molecule involved in the electrochemical process; $\mathrm{F}=$ Faraday constant $\left(96485 \mathrm{C} \mathrm{mol}^{-1}\right)$ and, $\mathrm{A}=$ electrode area $\left(0.07 \mathrm{~cm}^{2}\right)$.

The accumulated charge $(\mathrm{Q})$ was calculated from the area under one of the reversible peaks obtained for the redox active FePc in G-FePc catalyst and was found to be $25.35 \times 10^{-7} \mathrm{C}$. Thus, surface coverage of G-FePc was calculated to be $9.38 \times 10^{-11} \mathrm{~mol} \mathrm{~cm}^{-2}$. From this information, the weight $\%$ of $\mathrm{FePc}$ present in our electro-active material was calculated to be $0.0015 \%$. This ultra-low FePc loading in the G-FePc composite showed remarkable performance in the reduction reactions.

\section{Determination of NRR catalytic activity}

\section{A. Ammonia $\left(\mathrm{NH}_{3}\right)$ detection: Indophenol blue method}

From the cathodic chamber, $2 \mathrm{~mL}$ of the aliquot solution was taken and added to $2 \mathrm{~mL}$ of $\mathrm{NaOH}$ solution containing $5 \mathrm{wt} \%$ of each salicylic acid and sodium citrate. This is followed by the addition of $1 \mathrm{~mL}$ of $0.05 \mathrm{M} \mathrm{NaClO}$ and $0.2 \mathrm{~mL}$ of $0.5 \mathrm{wt} \%$ of $\mathrm{C}_{5} \mathrm{FeN}_{6} \mathrm{Na}_{2} \mathrm{O}$ (sodium nitroferricyanide) in water. The solution mixture was then incubated in dark for $2 \mathrm{~h}$ before UV-vis analysis at an absorbance of $650 \mathrm{~nm}$.

The concentration of ammonia evolved in the reduction process was determined by a calibration plot (concentration vs absorbance) obtained from a set of solutions containing known concentration of $\mathrm{NH}_{4} \mathrm{Cl}$ in $0.1 \mathrm{M} \mathrm{HCl}$. To each of these solutions, the abovementioned reagents were added and their absorbance were measured after a $2 \mathrm{~h}$ incubation time. The fitted plot shows a good linearity of absorbance with concentration of $\mathrm{NH}_{3}$ given by $-\left(y=0.0492 x+0.0167, R^{2}=0.989\right)$ 


\section{B. Hydrazine $\left(\mathrm{N}_{2} \mathrm{H}_{4}\right)$ detection: Watt and Chrisp method}

The indicator solution was prepared by dissolving $0.6 \mathrm{~g}$ of para-(dimethylamino) benzaldehyde in $30 \mathrm{~mL}$ absolute ethanol and $3 \mathrm{~mL}$ concentrated $\mathrm{HCl}(35 \%) .2 \mathrm{~mL}$ of this color agent was mixed to same volume of the electrolyte solution and the mixture was then incubated in dark for 15 minutes before performing the UV-vis characterization. A set of solutions with known concentration of $\mathrm{N}_{2} \mathrm{H}_{4}$ in $0.1 \mathrm{M} \mathrm{HCl}$ was used as calibration standard and their absorbance were measured at $\lambda=460 \mathrm{~nm}$. The fitted calibration plot obeys linearity of absorbance with concentration of $\mathrm{N}_{2} \mathrm{H}_{4}$ as $-\left(\mathrm{y}=1.873 \mathrm{x}+0.0465, \mathrm{R}^{2}=0.986\right)$. 


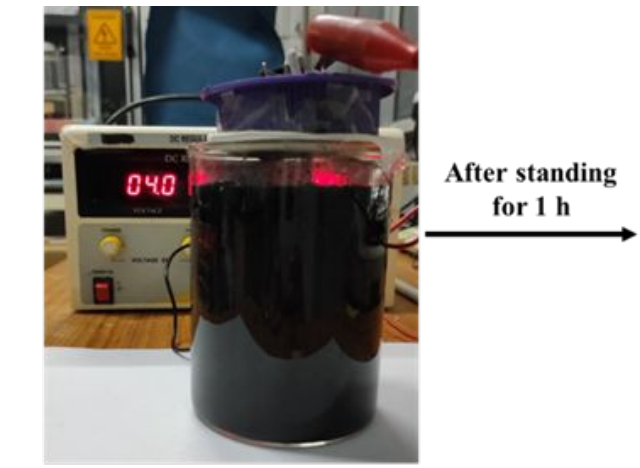

Cell Set-up for Electrophoretic Exfoliation

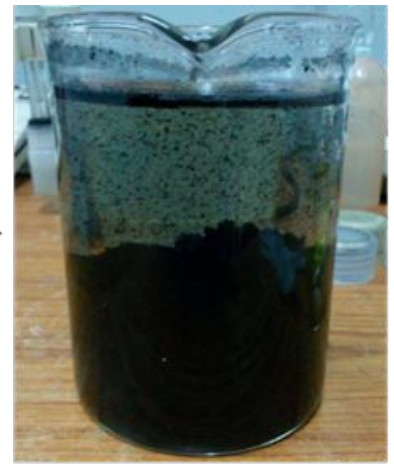

Material settled at the bottom

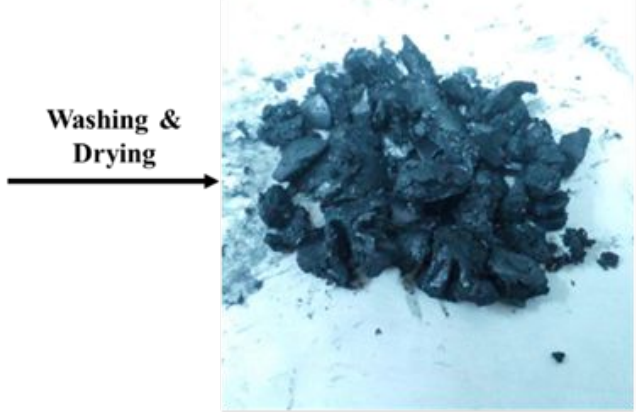

G-FePc catalyst

Figure S1. Large-scale exfoliation of graphite in $0.1 \mathrm{M} \mathrm{H}_{2} \mathrm{SO}_{4}$ and $\mathrm{FePc}$ at $+4 \mathrm{~V}$ bias voltage.

The electrophoretic exfoliation in large-scale was carried out with $(20 \times 2) \mathrm{cm}^{2}$ graphite foil in 1 litre electrolyte and sufficient amount of G-FePc material $(2.5 \mathrm{~g})$ was obtained as shown in Figure S1. 


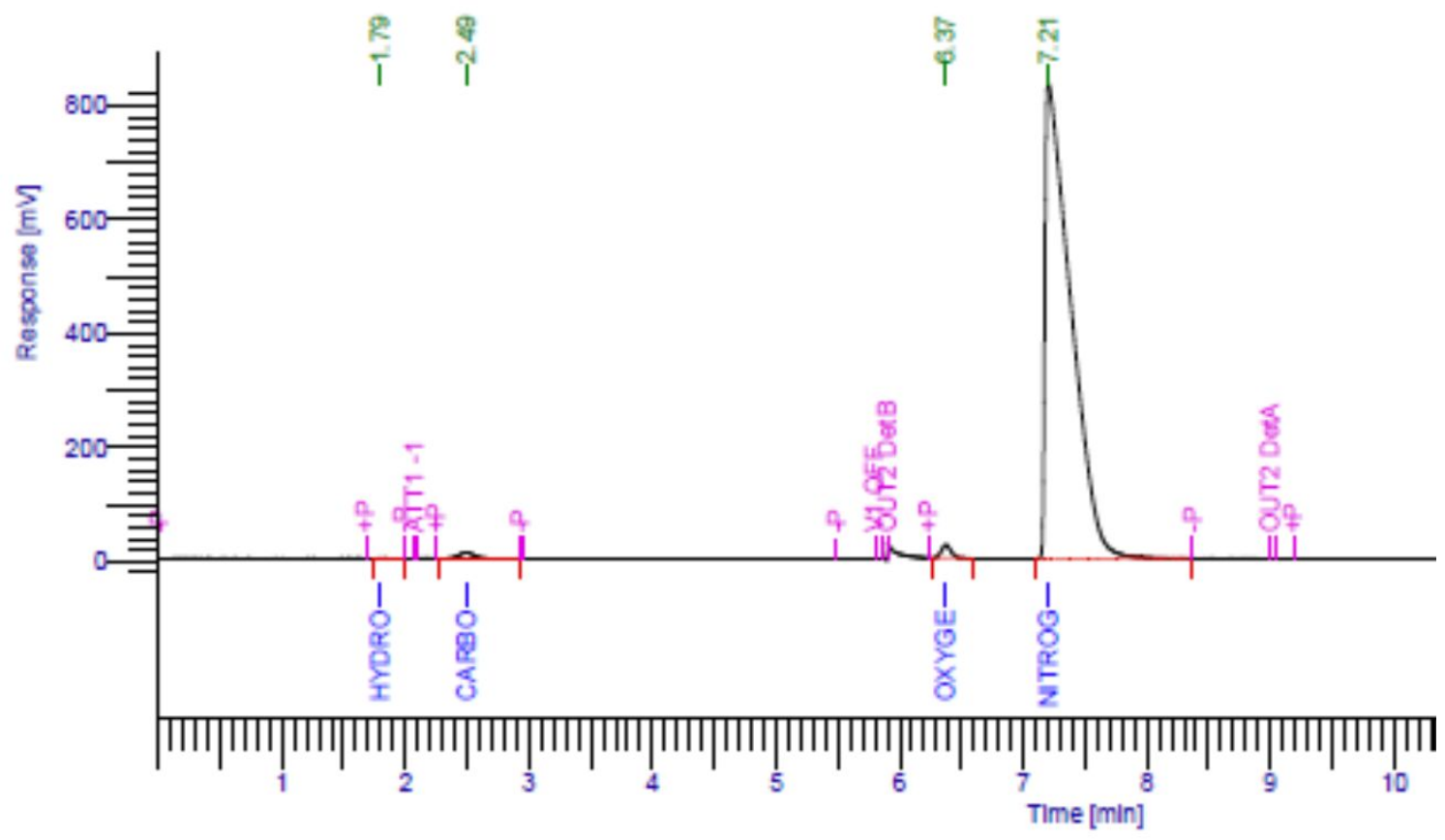

Figure S2. Gas chromatogram of nitrogen gas used for nitrogen reduction reaction studies 

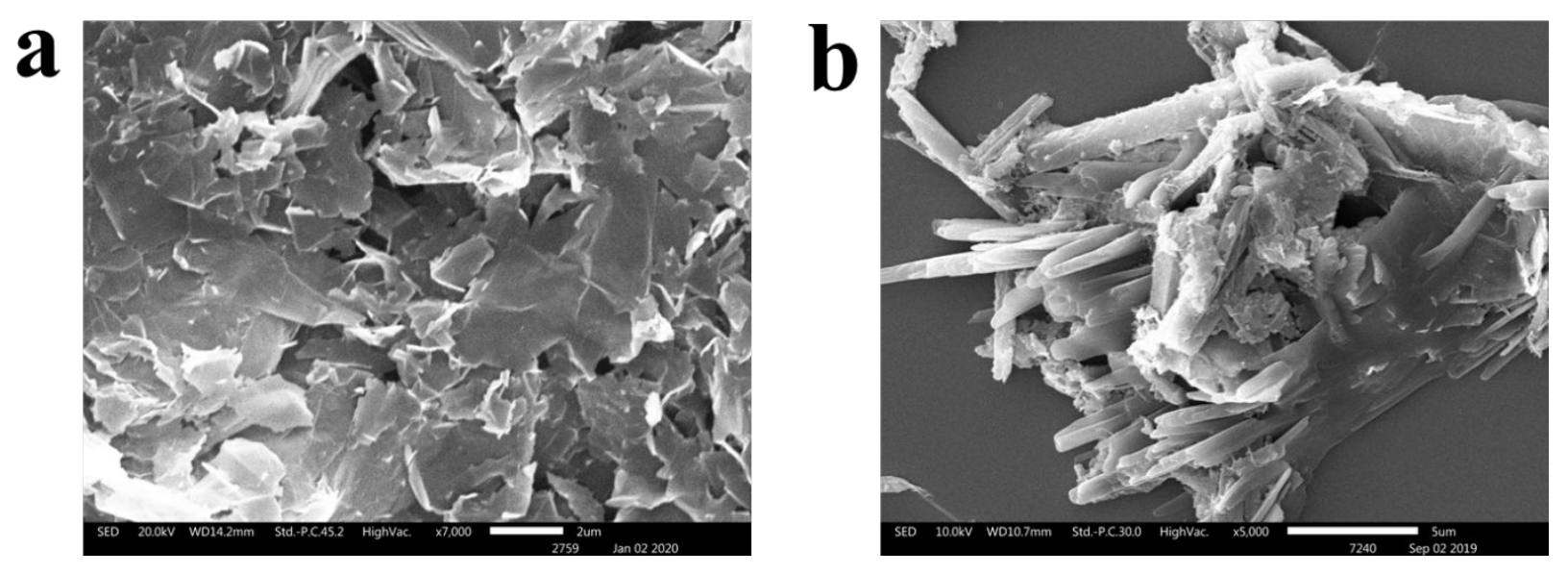

Figure S3. SEM images of (a) $\mathrm{G}-\mathrm{H}_{2} \mathrm{SO}_{4}$ (graphite exfoliated with $\mathrm{H}_{2} \mathrm{SO}_{4}$ ) and (b) graphite expanded with $\mathrm{HCl}$ in presence of rod-like FePc. 


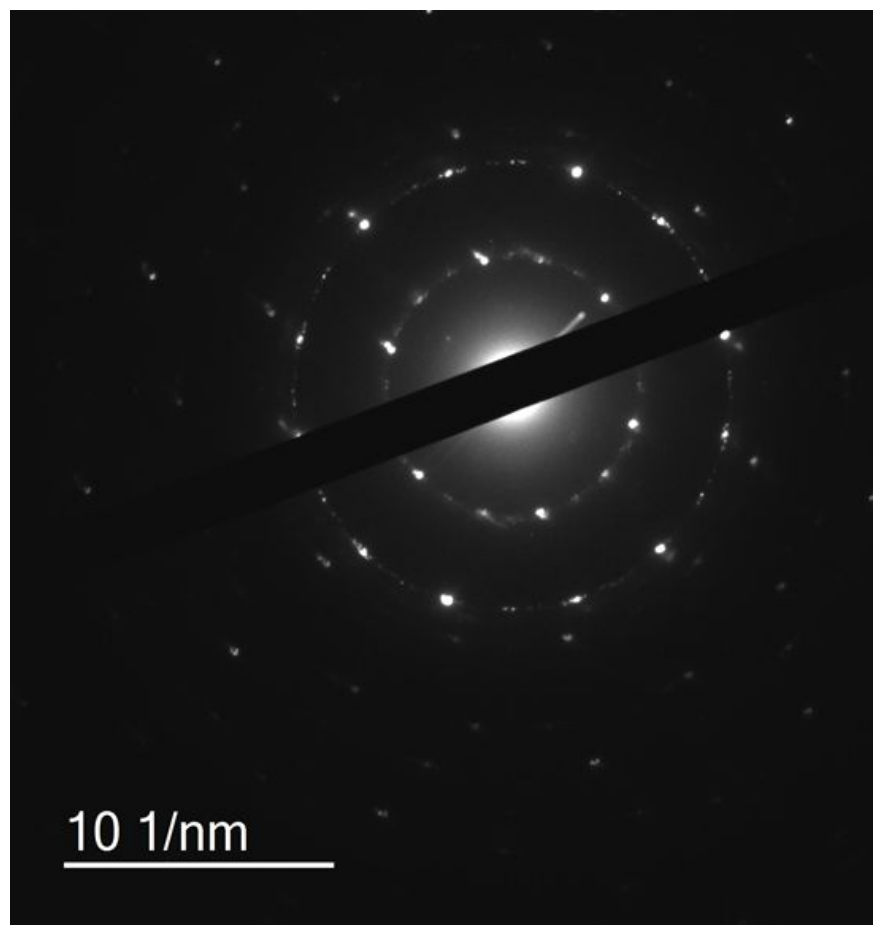

Figure S4. Selected area electron diffraction (SAED) pattern of G-FePc catalyst 


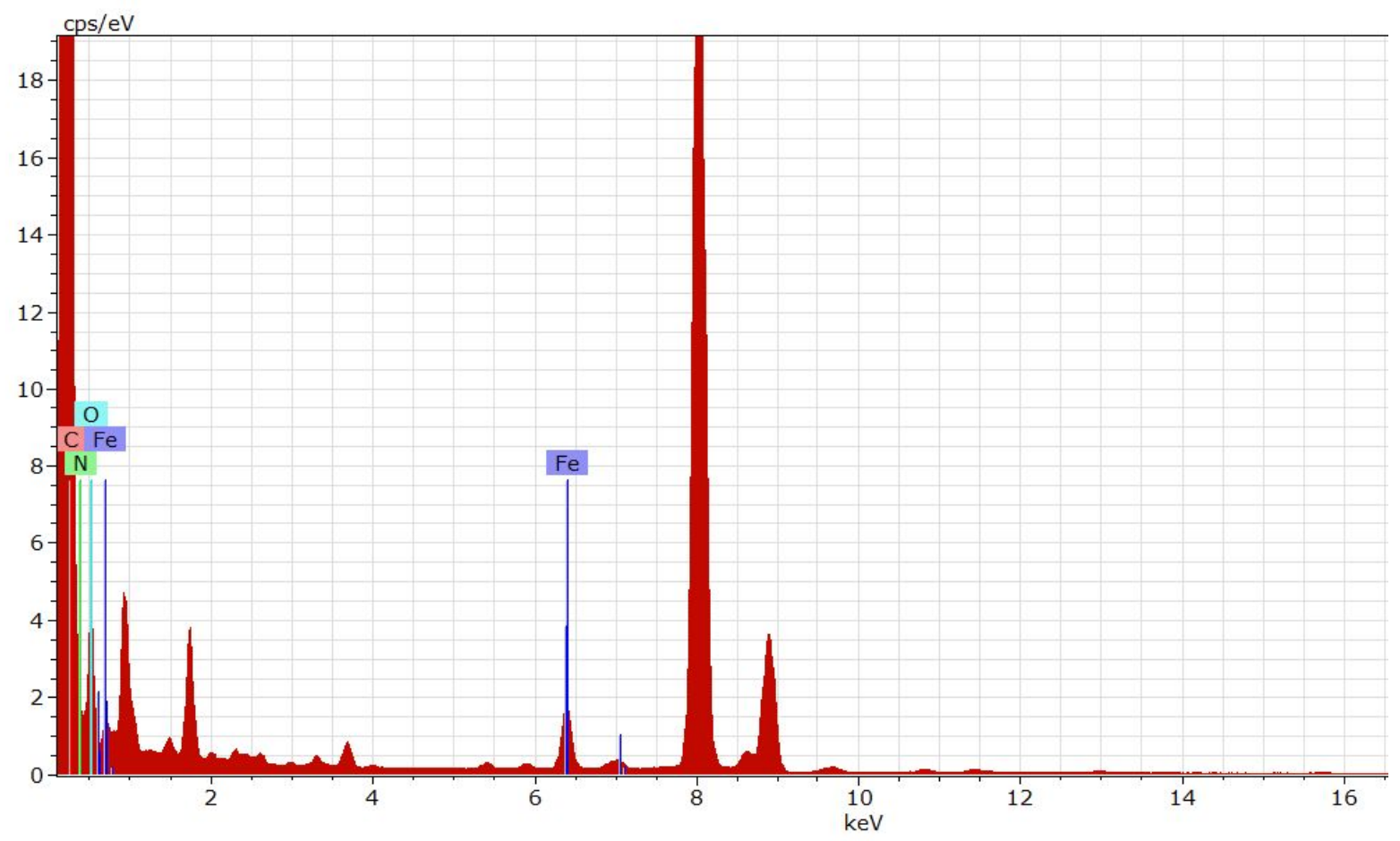

Figure S5. EDS analysis of G-FePc catalyst 

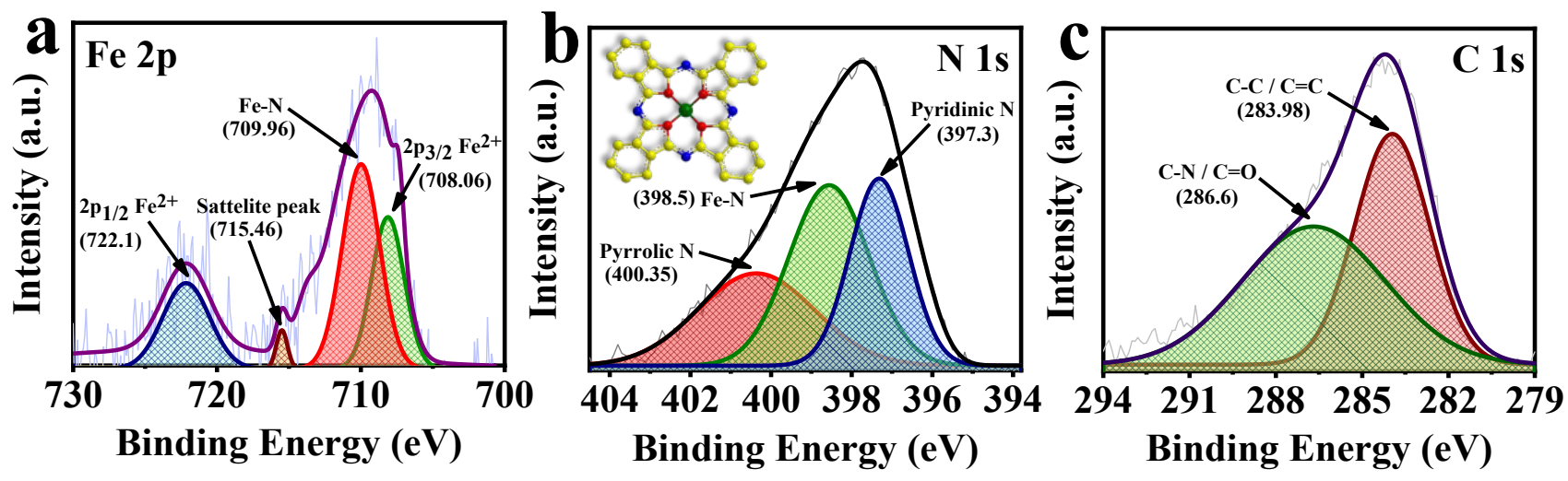

Figure S6. High resolution deconvoluted XPS spectra of (a) Fe 2p; (b) N 1s (inset showing the structure of iron phthalocyanine FePc denoting pyridinic $\mathrm{N}$ with blue, pyrrolic $\mathrm{N}$ with red and Fe with green which contributes to the $\mathrm{N}$ functionalities obtained in G-FePc catalyst); (c) C 1s of G-FePc catalyst. 

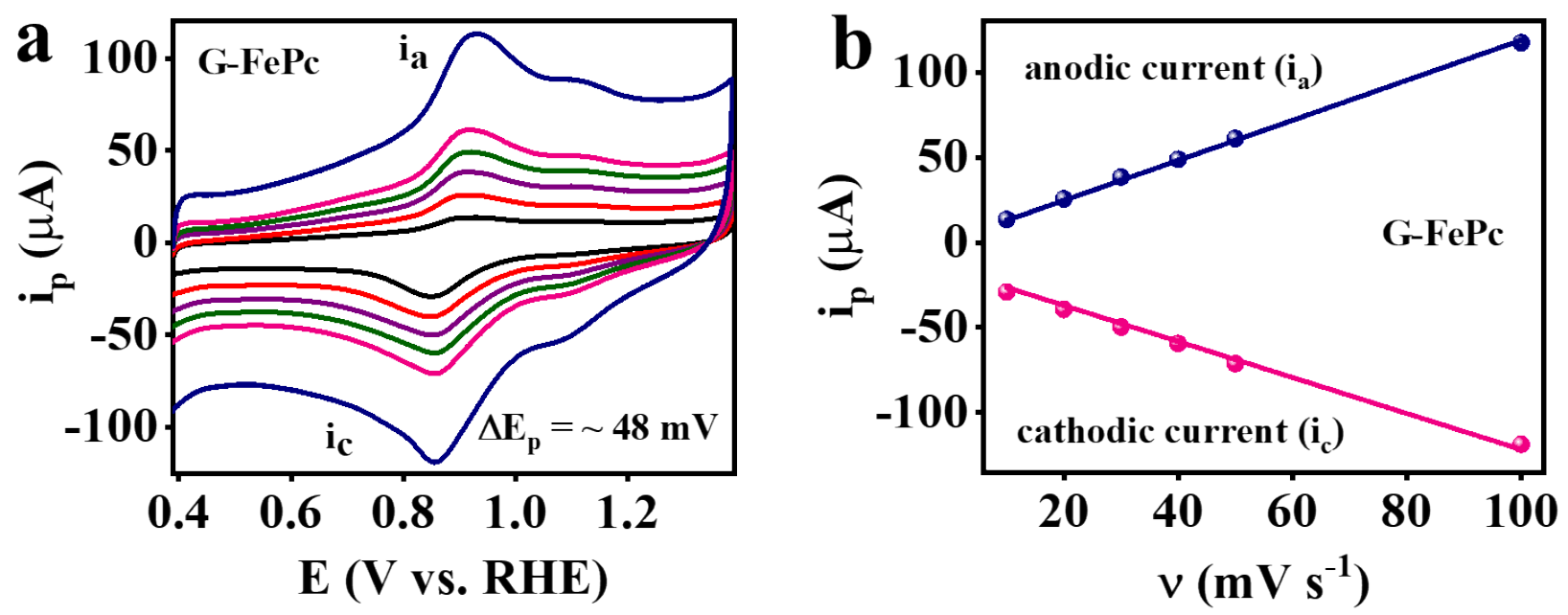

Figure S7. (a) Cyclic voltammetric response of G-FePc at different scan rate in $0.1 \mathrm{M} \mathrm{KOH}$; (b) Corresponding plot of current vs. scan rate $\left(0.01\right.$ to $\left.0.1 \mathrm{~m} \mathrm{~V} \mathrm{~s}^{-1}\right)$ 


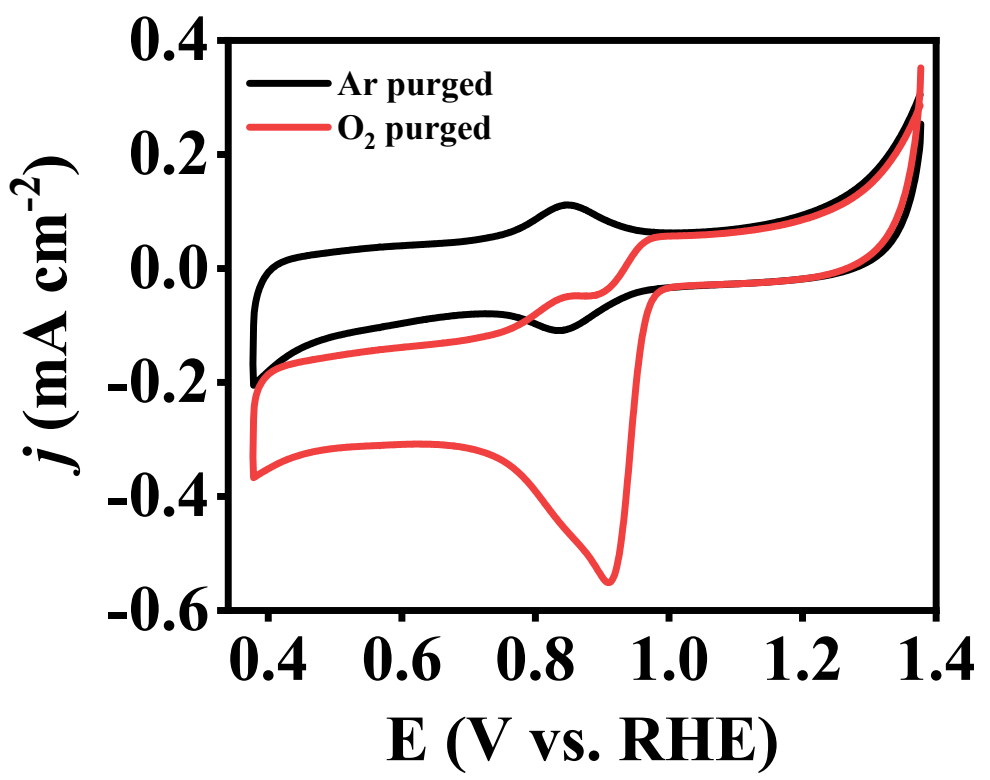

Figure S8. Cyclic voltammetry (CV) analysis of G-FePc catalyst in the presence of Ar and $\mathrm{O}_{2}$ saturated $0.1 \mathrm{M} \mathrm{KOH}$ electrolyte solution at $10 \mathrm{mV} \mathrm{s}^{-1}$ scan rate. 

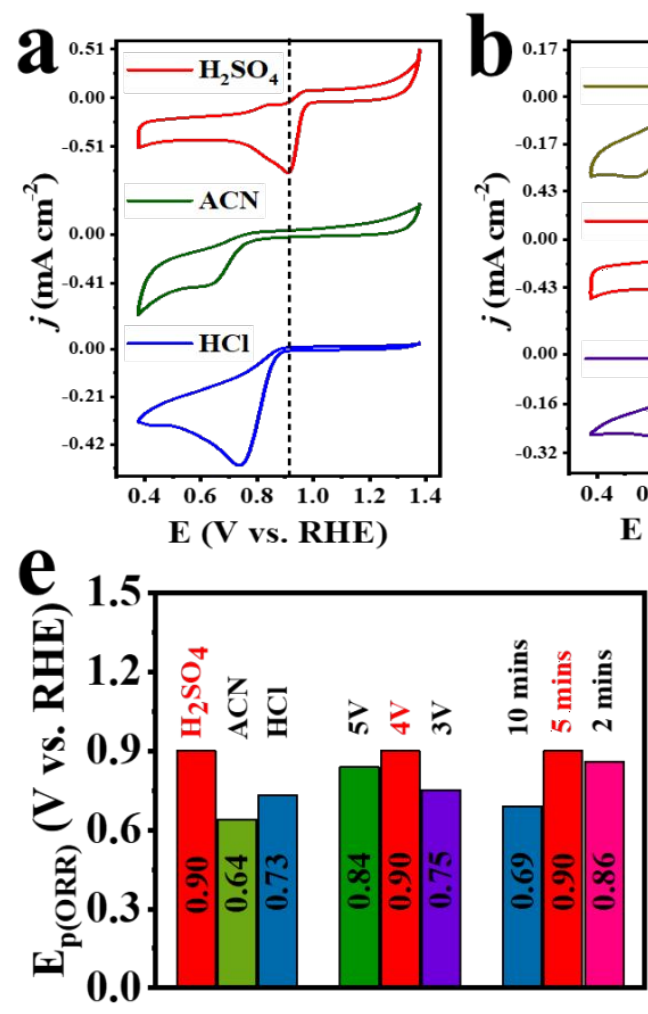
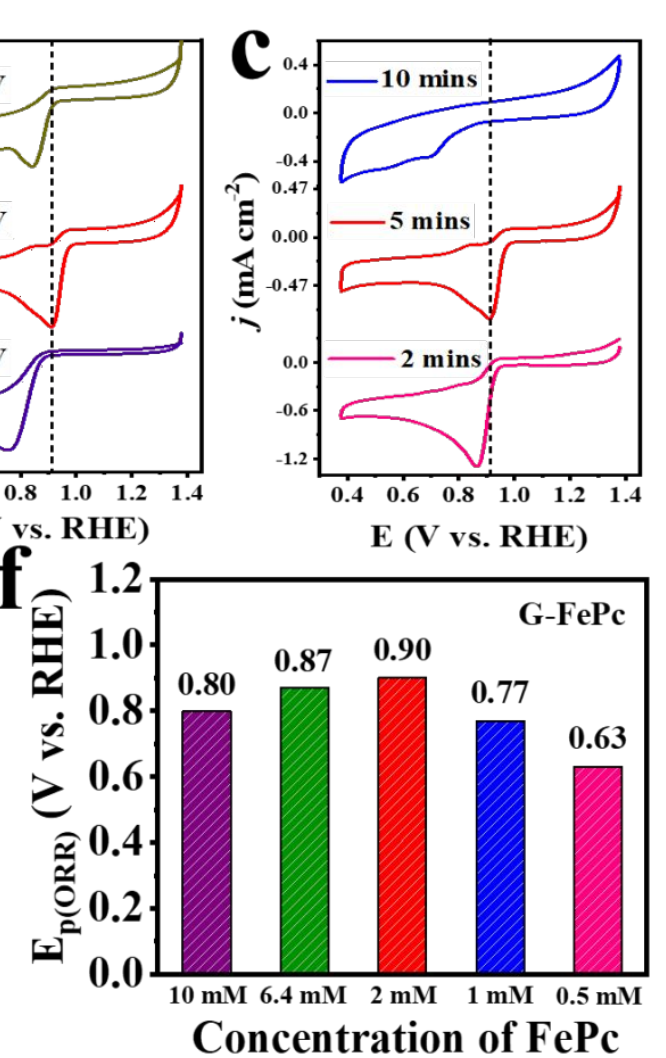

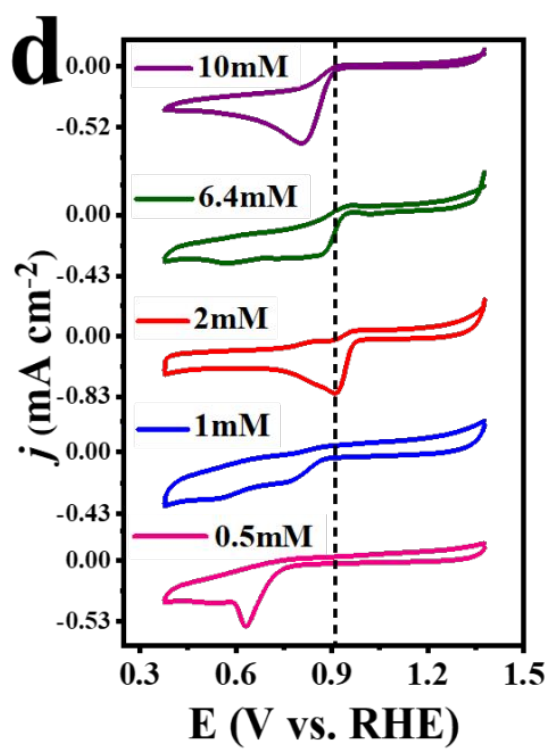

G-FePc: $\mathrm{H}_{2} \mathrm{SO}_{4}$, $4 \mathrm{~V}, 5 \mathrm{mins}, 2 \mathrm{mM}$

Figure S9. Comparative cyclic voltammetry $(\mathrm{CV})$ plots of as-synthesized catalysts in $\mathrm{O}_{2}$ saturated $0.1 \mathrm{M}$ $\mathrm{KOH}$ at $10 \mathrm{mV} \mathrm{s}^{-1}$ scan rate (a) with different solvents mediating the exfoliation of graphite, (b) at different operating bias voltage, (c) for different time periods, (d) with varied concentrations of FePc; (e, f) Bar plot analysis of all the synthesized catalysts on the basis of ORR peak potential $\mathrm{E}_{\mathrm{p}(\mathrm{ORR}) \text {. }}$ 

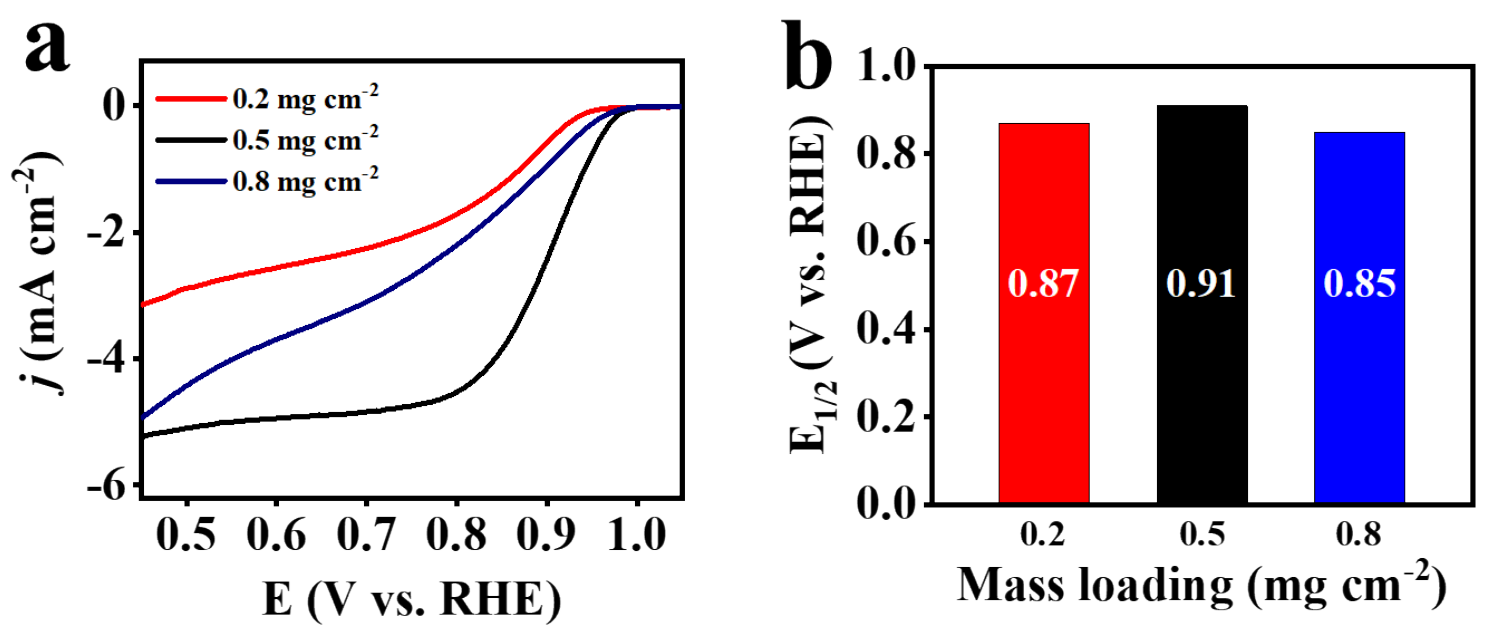

Figure S10. (a) Mass loading optimization of G-FePc catalyst using RDE technique at fixed $1600 \mathrm{rpm}$ under $\mathrm{O}_{2}$ saturated $0.1 \mathrm{M} \mathrm{KOH}$ electrolyte; (b) Comparative bar plot of ORR half-wave potentials $\left(\mathrm{E}_{1 / 2}\right)$ with varying catalytic mass loading. 


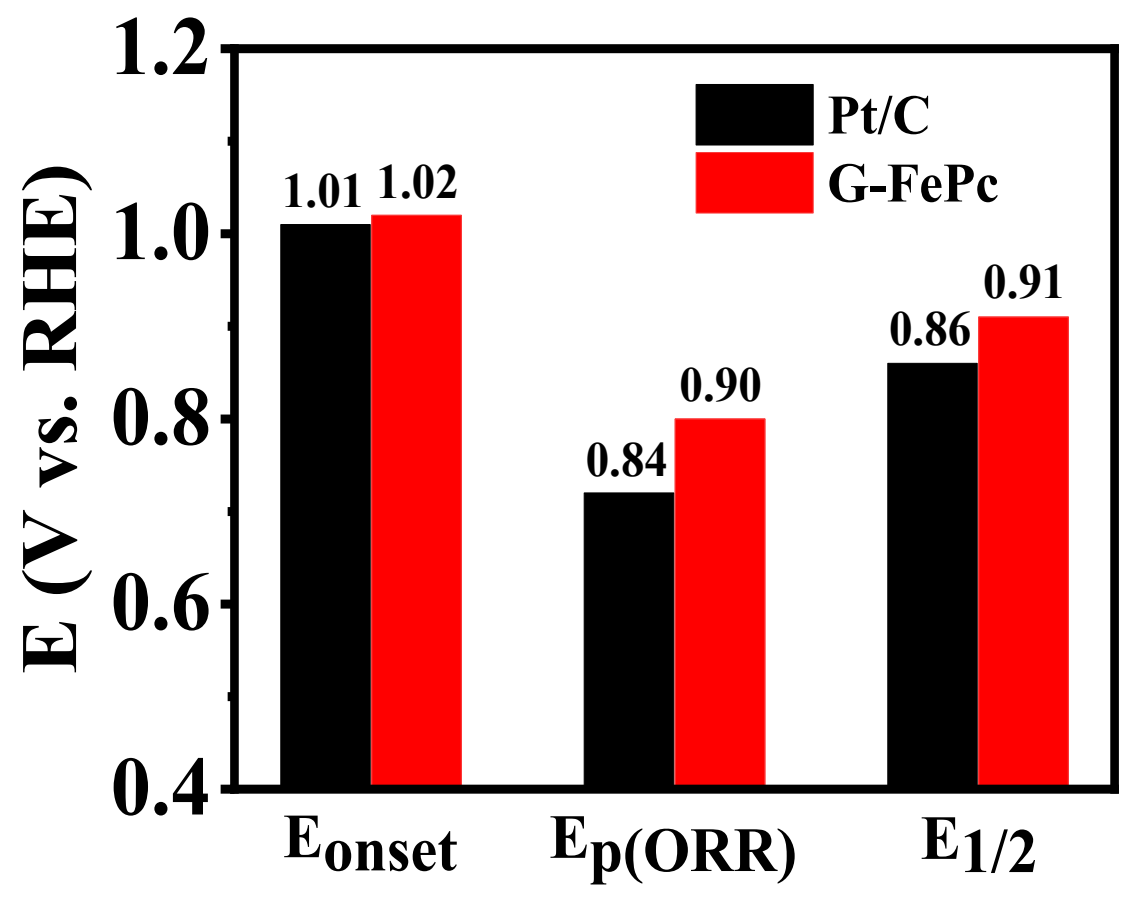

Figure S11. Comparative bar diagram representation of ORR onset potential ( $\left.\mathrm{E}_{\text {onset }}\right)$, peak potential $\left(\mathrm{E}_{\mathrm{p}(\mathrm{ORR})}\right)$ and half-wave potential $\left(\mathrm{E}_{1 / 2}\right)$ of $\mathrm{Pt} / \mathrm{C}$ and $\mathrm{G}-\mathrm{FePc}$ catalysts. 


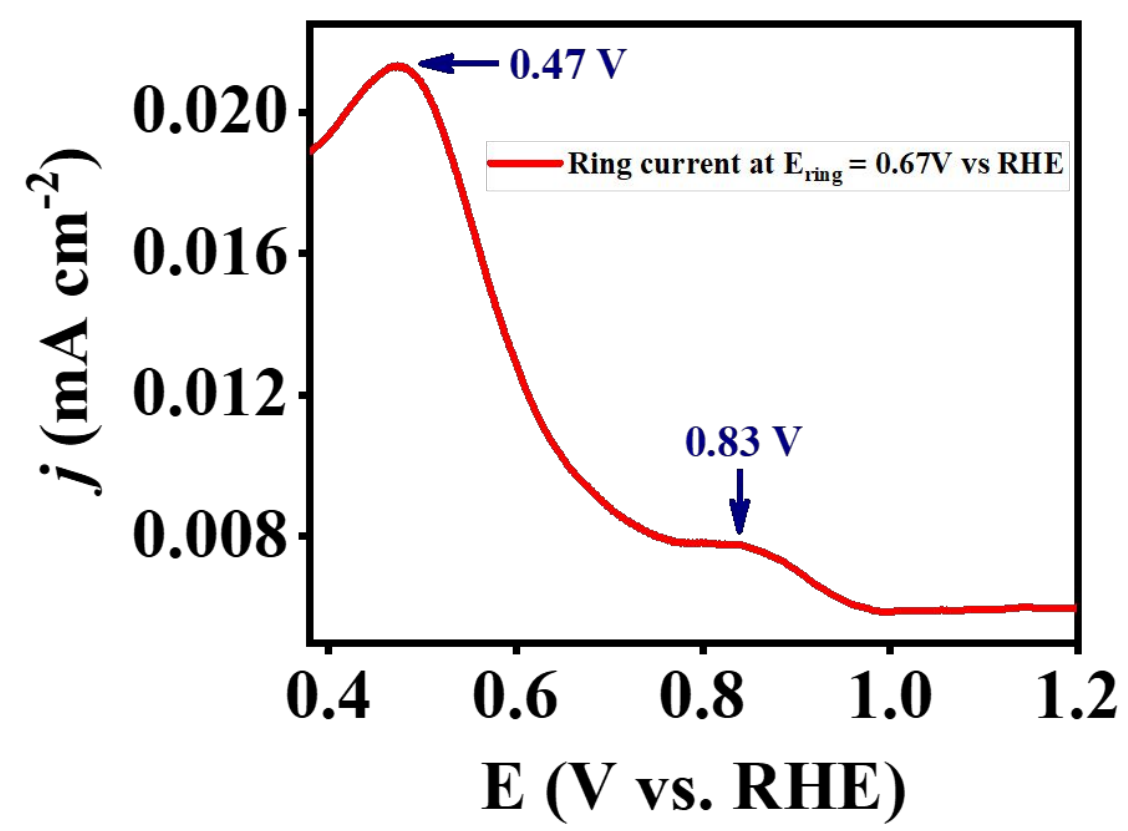

Figure S12. Ring current of G-FePc catalyst in $\mathrm{O}_{2}$ saturated $0.1 \mathrm{M} \mathrm{KOH}$ at $0.67 \mathrm{~V}$ vs. RHE applied ring potential at $1600 \mathrm{rpm}$. 


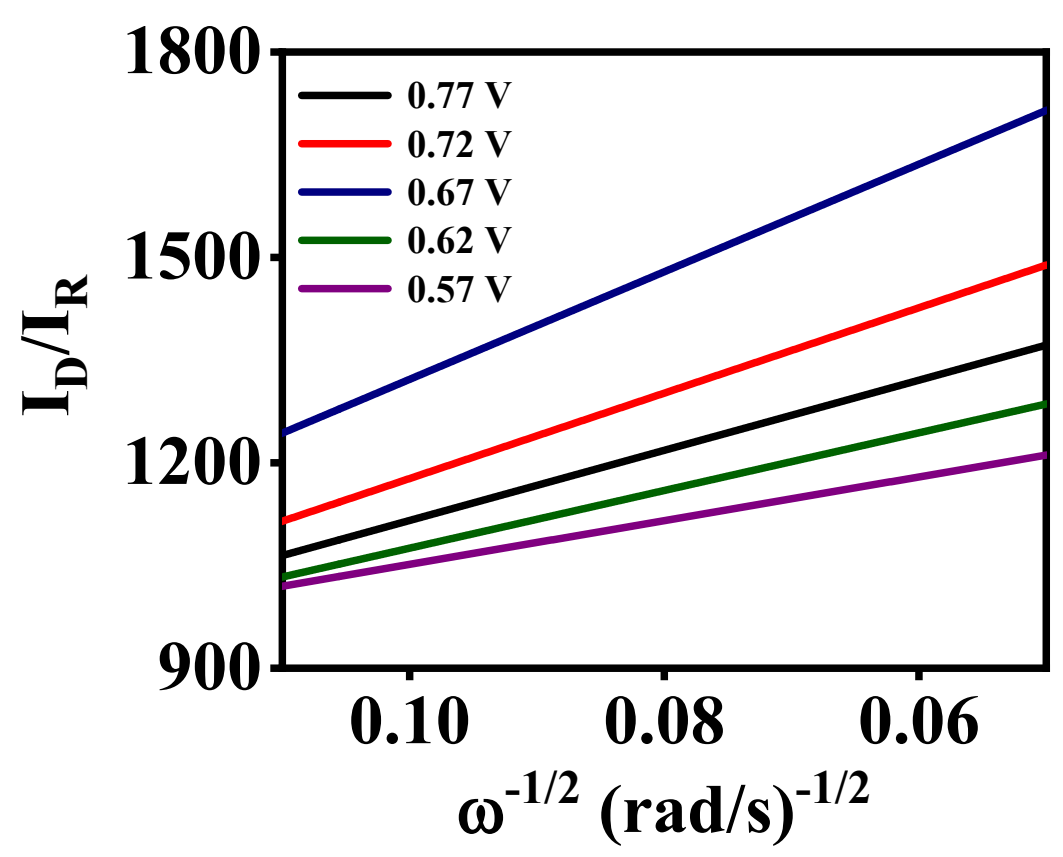

Figure S13. Plots of $I_{D} / I_{R}$ with respect to $\omega^{-1 / 2}$ for oxygen reduction at $k_{1} \neq 0, k_{2} \neq$ 0 and $\mathrm{k}_{3} \neq 0$ at different ring potentials.

Oxygen reduction reaction follows the following possible pathways-

When there is no oxidation or decomposition of $\mathrm{HO}_{2}^{-}, \mathrm{k}_{4}=\mathrm{k}_{-1}=0$ and $\mathrm{I}_{\mathrm{D}} / \mathrm{I}_{\mathrm{R}}$ (disk current/ring

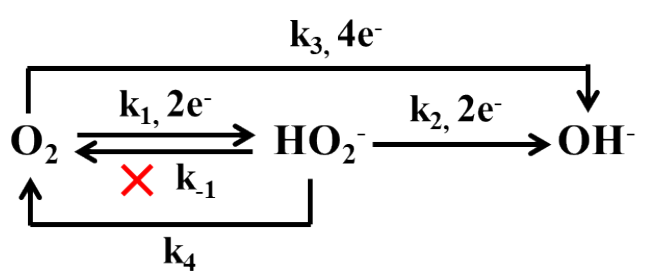

current) can be plotted against $\omega^{-1 / 2}$. The plot corresponds to a case when there is a direct 4 electron transfer of oxygen into $\mathrm{OH}^{-}$in $0.1 \mathrm{M} \mathrm{KOH}\left(\mathrm{k}_{3}\right)$. Not only that, the minimal amount of $\mathrm{HO}_{2}{ }^{-}$that is produced is extremely stable at the electrode surface and is feasible to further reduction to give the ultimate 4 electron product via $2+2$ electron reaction pathway $\left(\mathrm{k}_{1}+\right.$ $\left.\mathrm{k}_{2}\right)^{[1]}$ 


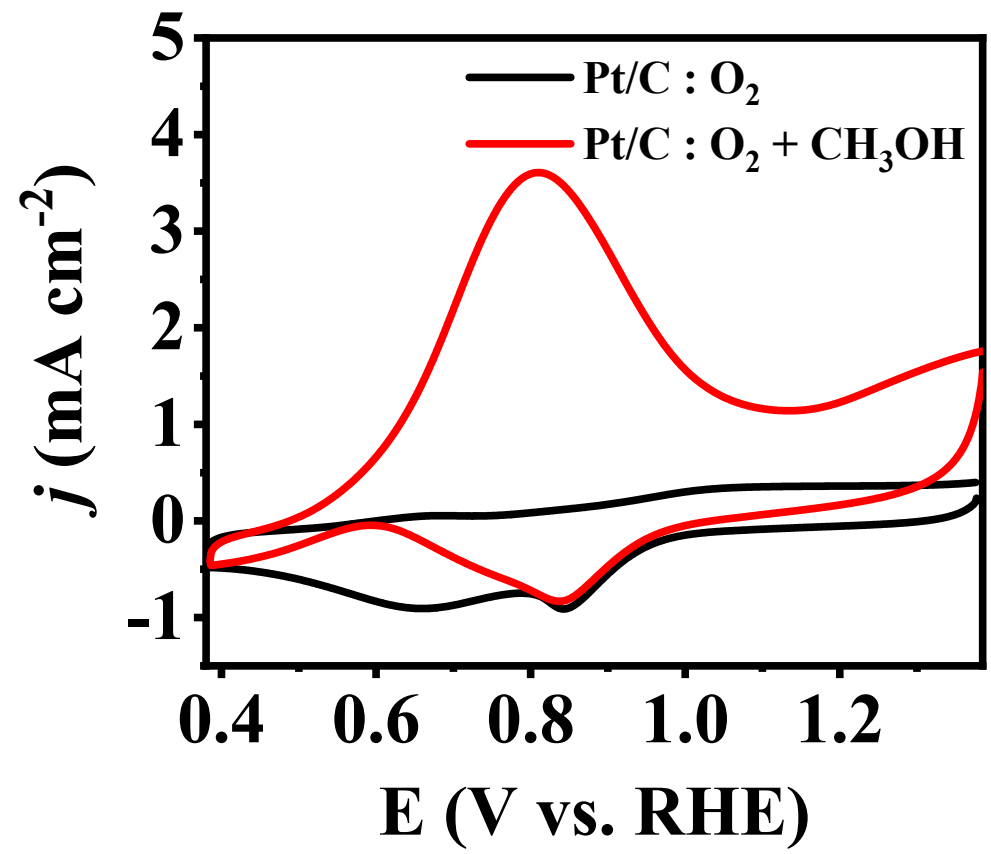

Figure S14. Cyclic voltammetry analysis of $\mathrm{Pt} / \mathrm{C}$ catalyst in $\mathrm{O}_{2}$ saturated $0.1 \mathrm{M}$ $\mathrm{KOH}$ solution in presence (red) and absence (black) of 1.0 M methanol. 

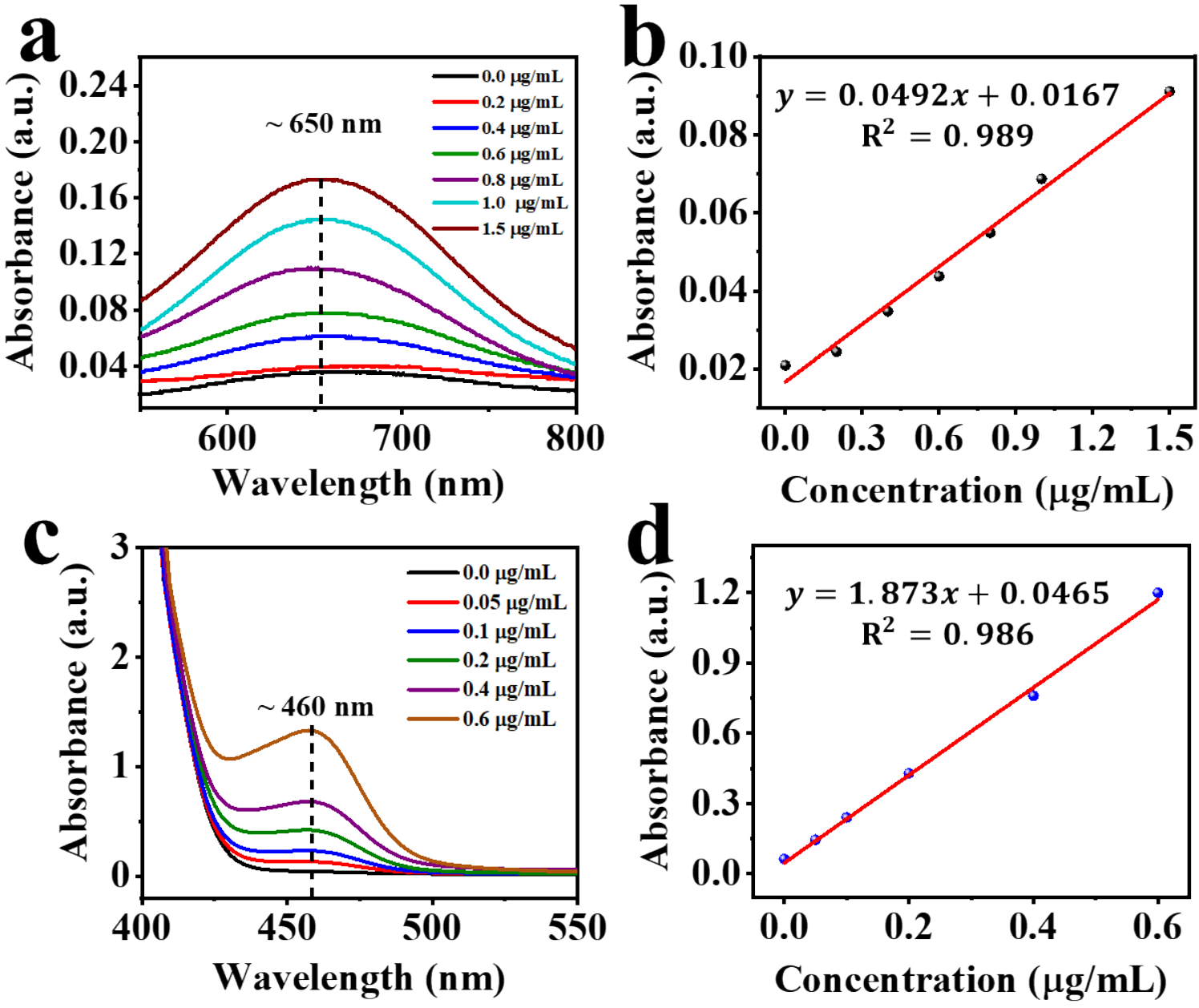

Figure S15. (a) UV-vis absorption spectra of indophenol blue formed from the $\mathrm{NH}_{4} \mathrm{Cl}$ standard solutions (of known concentrations) after incubated for $2 \mathrm{~h}$ at room temperature; (b) Ammonia - indophenol blue absorbance $(\sim 650 \mathrm{~nm})$ calibration plot used in this study; (c) UV-vis absorption spectra of standard solutions with different concentration of $\mathrm{N}_{2} \mathrm{H}_{4}$ after 15 min incubation time at room temperature; (d) Absorbance $(460 \mathrm{~nm})$ calibration plot used in this study. 


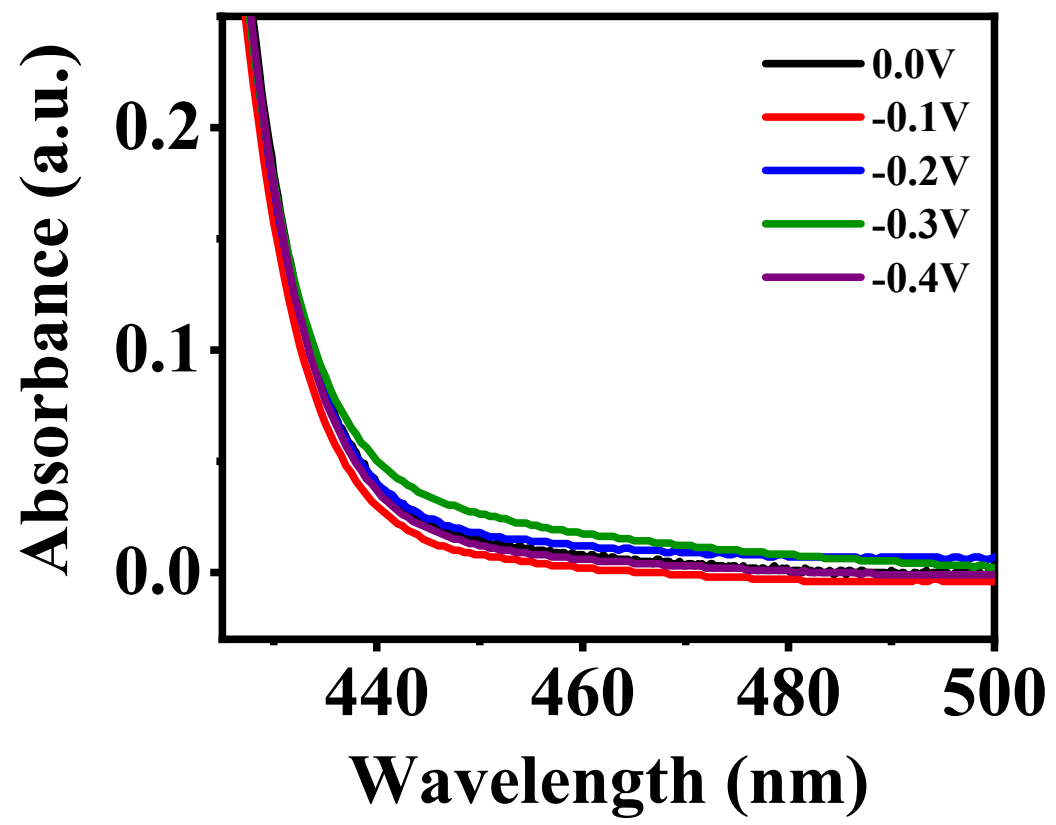

Figure S16. UV-vis absorption spectra for the detection of $\mathrm{N}_{2} \mathrm{H}_{4}$ at different applied potentials for $2 \mathrm{~h}$ of NRR measurements. 

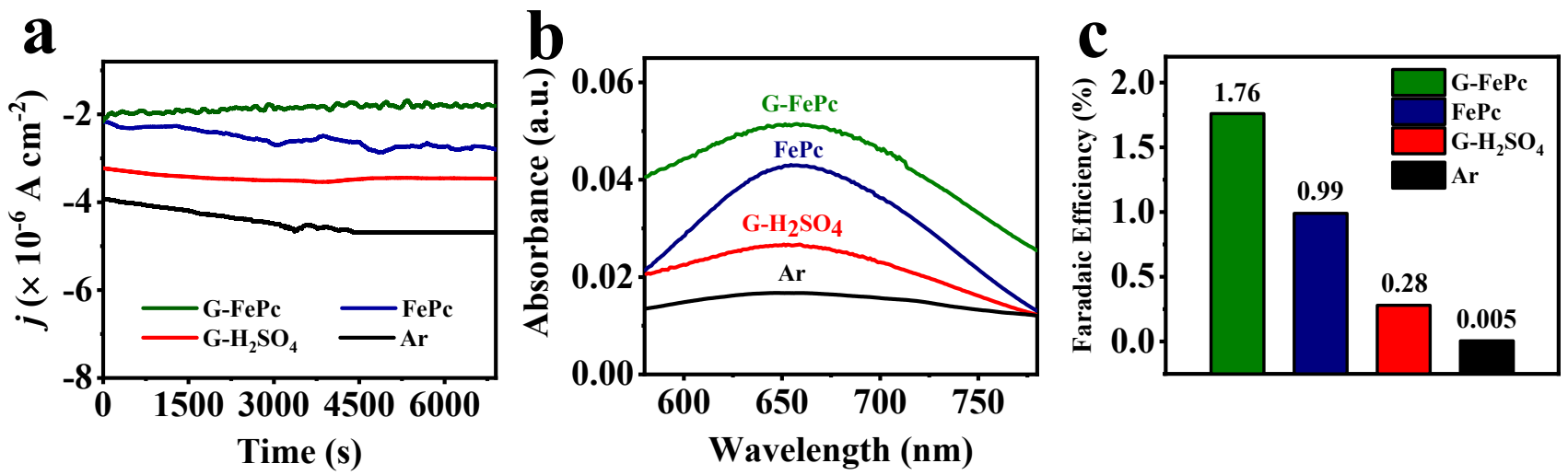

Figure S17. (a) j-t profile generated during the time dependent (2h) experiments at a constant applied potential of $-0.3 \mathrm{~V}$ vs. RHE for G-FePc catalyst in $\mathrm{N}_{2}$ and Ar saturated $0.1 \mathrm{M} \mathrm{HCl}$ and different control materials in presence of $\mathrm{N}_{2}$; (b) UV-vis absorption spectra of indophenol blue formed from the $\mathrm{NH}_{3}$ generated by the catalysts under investigation after $2 \mathrm{~h}$ of incubation time; (c) Corresponding Faradaic efficiency (\%) measurements of all the catalysts. 

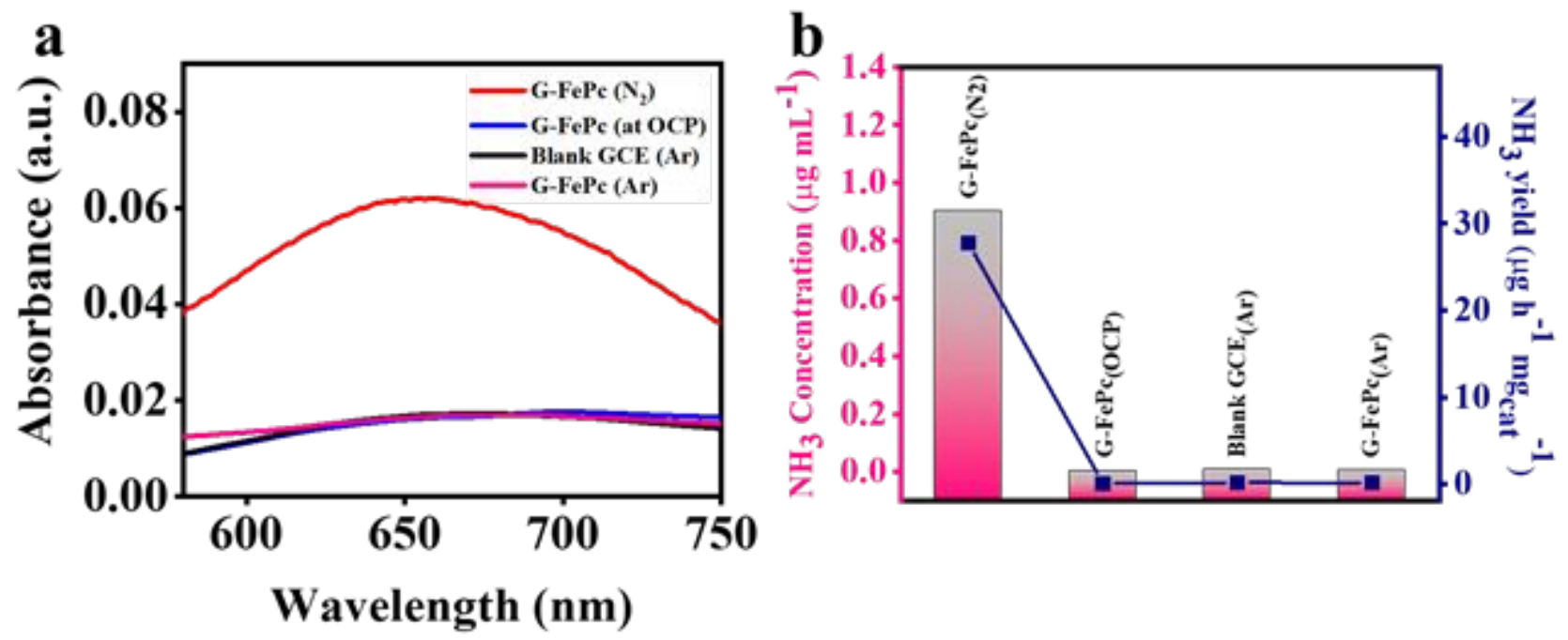

Figure S18. (a) UV-vis spectroscopic data of all controlled samples; (b) Comparative bar plot of concentration and yield of $\mathrm{NH}_{3}$ in all these cases. 

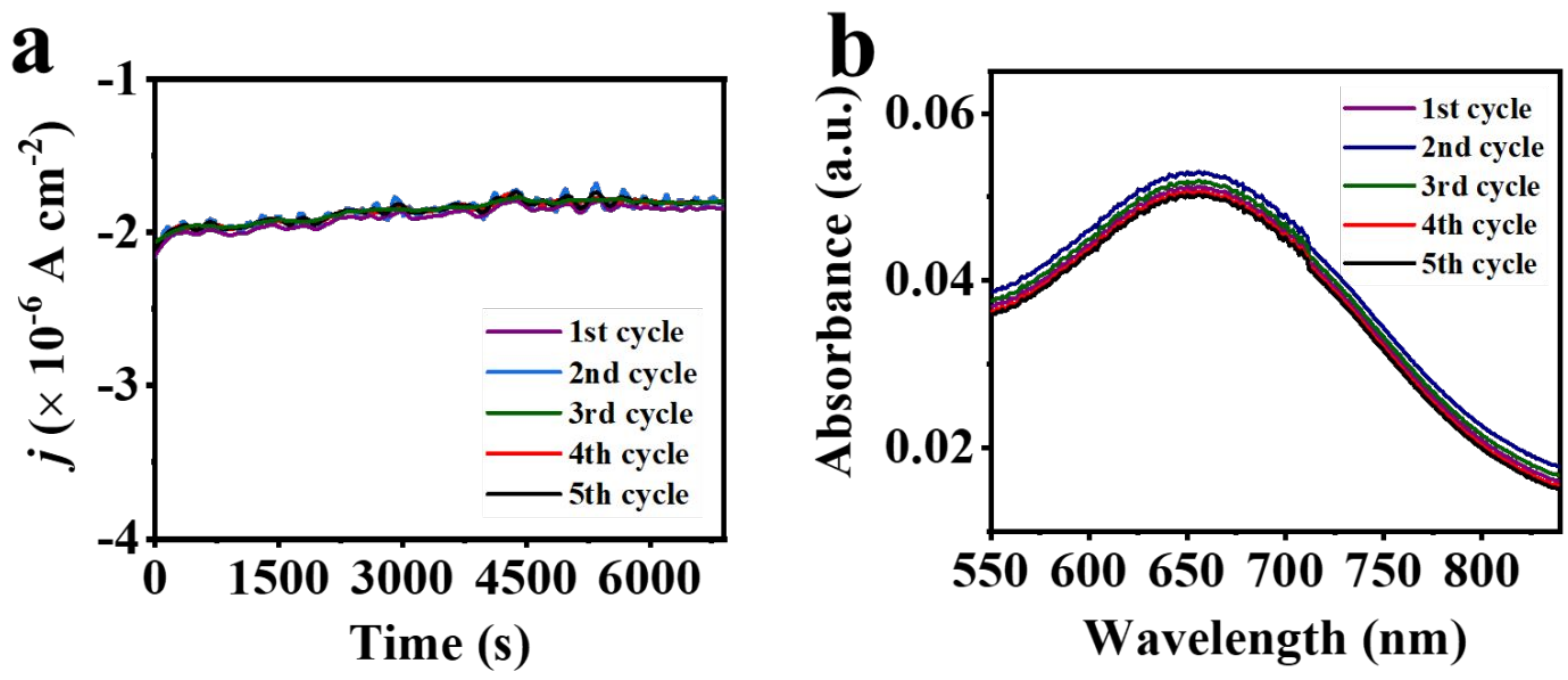

Figure S19. (a) Chronoamperometric response of G-FePc in $\mathrm{N}_{2}$ saturated $0.1 \mathrm{M} \mathrm{HCl}$ at $-0.3 \mathrm{~V}$ (vs. RHE) for five consecutive cycles (each for $2 \mathrm{~h}$ ); (b) UV-vis absorption spectra for detection of the evolved $\mathrm{NH}_{3}$ at $\sim 650 \mathrm{~nm}$. 
Table S1. XRD analysis of all the synthesized catalysts.

\begin{tabular}{|c|c|c|c|}
\hline SAMPLES & $\begin{array}{c}\text { PEAK POSITIONS } \\
(2 \theta)-(002) \text { PLANE }\end{array}$ & $\mathrm{d}_{002}$ SPACING & $\begin{array}{c}\text { CRYSTALLITE } \\
\text { SIZE L }\end{array}$ \\
\hline $\mathrm{G}-\mathrm{FePc}$ & 26.53 & 0.335 & 7.24 \\
\hline $\mathrm{G}-\mathrm{H}_{2} \mathrm{SO}_{4}$ & 25.95 & 0.343 & 3.06 \\
\hline
\end{tabular}


Table S2. Raman spectroscopic analysis of all the synthesized catalysts.

\begin{tabular}{|c|c|c|c|c|c|}
\hline SAMPLES & $\begin{array}{c}\text { G-BAND } \\
\left(\mathrm{cm}^{-1}\right)\end{array}$ & $\begin{array}{c}\text { D-BAND } \\
\left(\mathrm{cm}^{-1}\right)\end{array}$ & $\mathrm{I}_{\mathrm{D}} / \mathrm{I}_{\mathrm{G}}$ & $\mathrm{L}_{\mathrm{D}}(\mathrm{nm})$ & $\mathrm{n}_{\mathrm{D}}\left(\times 10^{11} \mathrm{~cm}^{-2}\right)$ \\
\hline $\mathrm{G}-\mathrm{FePc}$ & 1575.5 & 1353.3 & 0.32 & 24.24 & 0.979 \\
\hline $\mathrm{G}_{-} \mathrm{H}_{2} \mathrm{SO}_{4}$ & 1581.6 & 1353.3 & 0.45 & 20.53 & 1.366 \\
\hline
\end{tabular}


Table S3. Elemental analysis of G-FePc catalyst obtained from XPS analysis.

\begin{tabular}{|c|c|c|}
\hline ELEMENTS & BINDING ENERGY (eV) & ATOMIC (\%) \\
\hline Carbon (C) & 284.19 & 73.42 \\
\hline Nitrogen (N) & 398.17 & 18.54 \\
\hline Oxygen (O) & 531.62 & 5.67 \\
\hline Iron (Fe) & $708.92,722.1$ & 2.37 \\
\hline
\end{tabular}


Table S4. Electrocatalytic performances of synthesized catalysts and $\mathrm{Pt} / \mathrm{C}$ catalyst towards ORR

\begin{tabular}{|c|c|c|c|c|c|}
\hline CATALYSTS & ELECTROLYTE & $\begin{array}{c}\mathrm{E}_{\text {(onset) }} \\
\text { (V vs. RHE) }\end{array}$ & $\begin{array}{c}\mathrm{E}_{(1 / 2)} \\
(\mathrm{V} \text { vs. RHE) }\end{array}$ & $\begin{array}{c}\mathrm{E}_{\mathrm{p}(\mathrm{ORR})} \\
\text { (V vs. RHE) }\end{array}$ & $\begin{array}{c}\text { LIMITING CURRENT } \\
\text { DENSITY } \\
\left|\mathrm{J}_{\mathrm{L}}\right|\left(\mathrm{mA} \mathrm{cm}^{-2}\right)\end{array}$ \\
\hline G-FePc & \multirow{5}{*}{$0.1 \mathrm{M} \mathrm{KOH}$} & 1.02 & 0.91 & 0.90 & 5.4 \\
\hline G- $\mathrm{H}_{2} \mathrm{SO}_{4}$ & & 0.76 & 0.64 & 0.57 & 1.8 \\
\hline $\mathrm{FePc}$ & & 0.91 & 0.70 & 0.49 & 4.9 \\
\hline $\mathrm{G} / \mathrm{FePc}$ & & 0.90 & 0.77 & 0.64 & 4.65 \\
\hline $\mathrm{Pt} / \mathrm{C}$ & & 1.01 & 0.86 & 0.84 & 5.3 \\
\hline
\end{tabular}


Table S5. Summary of the electrocatalytic performance of recently reported FePc-based catalysts for ORR in $0.1 \mathrm{M} \mathrm{KOH}$ medium

\begin{tabular}{|c|c|c|c|c|c|}
\hline CATALYSTS & SYNTHESIS METHODS & $\begin{array}{l}\mathrm{E}_{\text {onset }}(\mathrm{V} \\
\text { vs. } \\
\text { RHE) }\end{array}$ & $\begin{array}{l}\mathrm{E}_{1 / 2}(\mathrm{~V} \\
\text { vs. } \\
\text { RHE) }\end{array}$ & $\begin{array}{l}\text { TAFEL } \\
\text { SLOPE } \\
\left.(\mathrm{mV} \mathrm{dec})^{-1}\right)\end{array}$ & REFERENCES \\
\hline G-FePc & $\begin{array}{ll}\text { Electrophoretic } & \text { exfoliation } \\
\text { (room temperature, } & 4 \mathrm{~V} \text { bias } \\
\text { voltage, } \mathbf{5} \text { minutes) } & \end{array}$ & 1.02 & 0.91 & 29 & THIS WORK \\
\hline g-FePc & $\begin{array}{l}\text { 1.GO synthesized from graphite } \\
\text { powder (modified Hummer's } \\
\text { method) } \\
\text { 2.Graphene sheets obtained from } \\
\text { partial reduction of GO } \\
\text { 3. Mixing of FePc-dispersed } \\
\text { DMF solution to graphene } \\
\text { solution ( } \mathbf{7} \text { h stirring) }\end{array}$ & 0.98 & 0.88 & - & [2] \\
\hline FePc-Py-CNT & $\begin{array}{l}\text { 1. Functionalization of CNTs with } \\
\text { Py groups by diazonium } \\
\text { reaction } \\
\text { 2.Reflux of Py-CNT with FePc in } \\
\text { tetrahydrofuran (Ar atmosphere) }\end{array}$ & $>1.05$ & 0.915 & 27 & {$[3]$} \\
\hline FePc/CB-EC600 & $\begin{array}{l}\text { 1.Graphene sheets obtained from } \\
\text { thermal reduction of GO } \mathbf{( 9 0 0} \\
\left.{ }^{\circ} \mathbf{C}, \mathbf{1} \mathbf{~ h}\right) \\
\text { 2.FePc/CB obtained via ball- } \\
\text { milling followed by vacuum } \\
\text { drying for } 24 \mathrm{~h}\end{array}$ & - & 0.91 & - & [4] \\
\hline MWNT/FePc-SH & $\begin{array}{l}\text { FePc and MWNTs were shaken } \\
(\text { r.t, } 20 \mathrm{~h}) \text {, sonicated }(6 \mathrm{~h}) \text {, } \\
\text { refluxed }\left(\mathbf{8 0}{ }^{\circ} \mathbf{C}, \mathbf{2 0} \mathbf{~ h} \text { in } 40 \mathrm{~mL}\right. \\
\text { THF) }\end{array}$ & 0.971 & 0.86 & 36 & [5] \\
\hline $\mathrm{FePc} / \mathrm{SWCNT}$ & $\begin{array}{l}\text { Ultrasonication and stirring (22 } \\
\text { h) }\end{array}$ & 0.957 & 0.87 & - & [6] \\
\hline $\mathrm{FePc} / \mathrm{MoS}_{2}$ & Hydrothermal $\left(200^{\circ} \mathrm{C}, 12 \mathrm{~h}\right)$ & - & 0.89 & 32 & [7] \\
\hline FePc-HCNTs & $\begin{array}{l}\text { 1.MWCNTs subjected to heat } \\
\text { treatment }\left(\mathbf{5 0 0}{ }^{\circ} \mathbf{C}, \mathbf{1} \mathbf{~ h}\right) \\
\text { 2.Hummer's method } \\
\text { 3.Stirring }(\mathbf{6} \mathbf{~ h})\end{array}$ & 0.937 & 0.85 & 32 & {$[8]$} \\
\hline FePc/N-GP950 & $\begin{array}{l}\text { 1.Electrochemical exfoliation of } \\
\text { graphite } \\
\text { 2.Heat-treatment at } 950{ }^{\circ} \mathrm{C} \text { in } \\
\text { argon }(60 \mathrm{~min}) \text { and in ammonia } \\
(15 \mathrm{~min}) \\
3 . \text { Stirring }(2 \mathrm{~h}) \text { with heating ( } \\
\left.65^{\circ} \mathrm{C}\right)\end{array}$ & 0.97 & 0.89 & 30 & [9] \\
\hline FePc-NG & $\begin{array}{l}\text { 1.GO prepared by modified } \\
\text { Hummer's method } \\
\text { 2.Hydrothermal }\left(200{ }^{\circ} \mathbf{C}, 12 \text { h) }\right. \\
\text { 3.Sonication }(1 \mathrm{~h})\end{array}$ & 0.967 & - & - & [10] \\
\hline $\mathrm{Pc}-\mathrm{FePc} / \mathrm{Mn}-\mathrm{GCB}$ & $\begin{array}{l}\text { 1.High temperature } \\
\text { graphitization }\left(2800{ }^{\circ} \mathbf{C}, \mathbf{1} \mathbf{h}\right), \\
\text { acidification }\left(60^{\circ} \mathrm{C}, \mathbf{5} \mathbf{h}\right)\end{array}$ & - & 0.90 & 42 & [11] \\
\hline
\end{tabular}




\begin{tabular}{|c|c|c|c|c|c|}
\hline & 2. Sonication & & & & \\
\hline FePc-ERGO & $\begin{array}{l}\text { 1. Heating }\left(155^{\circ} \mathrm{C}, 45 \mathrm{~min}\right) \\
\text { 2.Stirring }(6 \mathrm{~h})\end{array}$ & 0.966 & 0.89 & - & {$[12]$} \\
\hline FePc-RCNTs & $\begin{array}{l}\text { 1. Heating }\left(500{ }^{\circ} \mathbf{C}, \mathbf{1 ~ h}\right) \\
\text { 2.Stirring, hydrothermal } \quad(120 \\
\left.{ }^{\circ} \mathbf{C}, \mathbf{2 ~ h}\right)\end{array}$ & 0.951 & 0.86 & 38 & {$[13]$} \\
\hline
\end{tabular}

g-FePc: graphene-iron phthalocyanine; FePc-Py-CNT: iron phthalocyanine on pyridine functionalized single-walled carbon nanotube; FePc/CB-EC600: iron phthalocyanine coated on carbon-black-Ketjenblack; MWNT/FePc-SH: multi-wall carbon nanotube/iron phthalocyanine-shaking; FePc/SWCNT: iron phthalocyanine coated on single-walled carbon nanotube; FePc/N-GP: iron phthalocyanine into a surface of nitrogen-doped electrochemical exfoliated graphene; FePc-NG: iron phthalocyanine-nitrogen-doped graphene composite; PcFePc/Mn-GCB: phthalocyanine tethered iron phthalocyanine complex on the Mn-modified Graphitized carbon black; FePc-ERGO: iron phthalocyanine functionalized electrochemically reduced graphene oxide; FePc-RCNTs: iron phthalocyanine-reduced carbon nanotubes. 
Table S6a. Electrocatalytic NRR performance of G-FePc catalyst towards NRR in $0.1 \mathrm{M}$ $\mathrm{HCl}$ at different potentials

\begin{tabular}{|c|c|c|}
\hline POTENTIAL $(\mathrm{V}$ vs. RHE) & $\mathrm{NH}_{3}$ YIELD $\left(\mu \mathrm{g} \mathrm{h}^{-1} \mathrm{mg}_{\mathrm{cat}^{-1}}{ }^{-1}\right.$ & FARADAIC EFFICIENCY (\%) \\
\hline 0.0 & 10.65 & 0.56 \\
\hline-0.1 & 16.45 & 1.34 \\
\hline-0.2 & 20.99 & 2.04 \\
\hline-0.3 & 27.74 & 1.76 \\
\hline-0.4 & 6.6 & 0.21 \\
\hline
\end{tabular}

Table S6b. Electrocatalytic NRR performance of all the synthesized catalysts at $-0.3 \mathrm{~V}$

\begin{tabular}{|c|c|c|c|}
\hline CATALYSTS & ELECTROLYTE & $\begin{array}{c}\mathrm{NH}_{3} \text { YIELD } \\
\left(\mu \mathrm{g} \mathrm{h}^{-1} \mathrm{mg}_{\mathrm{cat}^{-1}}\right)\end{array}$ & $\begin{array}{c}\text { FARADAIC } \\
\text { EFFICIENCY (\%) }\end{array}$ \\
\hline $\mathrm{G}-\mathrm{FePc}$ & $0.1 \mathrm{M} \mathrm{HCl}\left(\mathrm{N}_{2}\right)$ & 27.74 & 1.76 \\
\hline $\mathrm{G}_{-} \mathrm{H}_{2} \mathrm{SO}_{4}$ & $0.1 \mathrm{M} \mathrm{HCl}\left(\mathrm{N}_{2}\right)$ & 5.65 & 0.28 \\
\hline $\mathrm{FePc}$ & $0.1 \mathrm{M} \mathrm{HCl}\left(\mathrm{N}_{2}\right)$ & 16.06 & 0.99 \\
\hline $\mathrm{G}-\mathrm{FePc}$ & $0.1 \mathrm{M} \mathrm{HCl}(\mathrm{Ar})$ & 0.15 & 0.005 \\
\hline
\end{tabular}

Table S6c. Concentration and yield of $\mathrm{NH}_{3}$ formed with different controlled samples

\begin{tabular}{|c|c|c|}
\hline & Concentration $\left(\mu \mathrm{g} \mathrm{mL} \mathrm{L}^{-1}\right)$ & $\mathrm{NH}_{3}$ yield $\left(\mu \mathrm{g} \mathrm{h}^{-1} \mathrm{mg}_{\mathrm{cat}}{ }^{-1}\right)$ \\
\hline $\mathrm{G}-\mathrm{FePc}\left(\mathrm{N}_{2}\right)$ & 0.901 & 27.74 \\
\hline G-FePc (OCP) & 0.002 & 0.08 \\
\hline Blank GCE (Ar) & 0.006 & 0.19 \\
\hline G-FePc (Ar) & 0.005 & 0.15 \\
\hline
\end{tabular}


Table S7. Elemental analysis of G-FePc catalyst obtained from EDS analysis before and after NRR.

\begin{tabular}{|c|c|c|}
\hline ELEMENTS & ATOMIC \% BEFORE NRR & ATOMIC \% AFTER NRR \\
\hline Carbon (C) & 75.01 & 75.64 \\
\hline Nitrogen (N) & 12.81 & 13.72 \\
\hline Oxygen (O) & 11.97 & 10.57 \\
\hline Iron (Fe) & 0.21 & 0.06 \\
\hline
\end{tabular}


Table S8. Summary of the electrocatalytic performance of recently reported C-supported

\begin{tabular}{|c|c|c|c|c|c|c|c|}
\hline CATALYSTS & $\begin{array}{l}\text { SYNTHESIS } \\
\text { METHODS }\end{array}$ & ELECTROLYTE & $\begin{array}{l}\mathrm{NH}_{3} \\
\text { YIELD } \\
\left(\mu \mathrm{g} \mathrm{h}^{-1}\right. \\
\left.\mathrm{mg}_{\mathrm{cat}^{-1}}{ }^{-1}\right)\end{array}$ & $\begin{array}{l}\mathrm{NH}_{3} \\
\text { YIELD } \\
\left(\mu \mathrm{g} \mathrm{h}^{-1}\right. \\
\left.\mathrm{cm}^{-2}\right)\end{array}$ & $\begin{array}{l}\text { POTENTIAL } \\
\text { (V vs. RHE) }\end{array}$ & METHOD & REFERENCES \\
\hline G-FePc & $\begin{array}{l}\text { Electrophoretic } \\
\text { exfoliation (room } \\
\text { temperature, 4 V } \\
\text { bias voltage, } \quad \mathbf{5} \\
\text { minutes) }\end{array}$ & $0.1 \mathrm{M} \mathrm{HCl}$ & 27.74 & 12.87 & \begin{tabular}{ll|}
-0.3 \\
\end{tabular} & $\begin{array}{l}\text { Indophenol } \\
\text { blue method }\end{array}$ & THIS WORK \\
\hline $\begin{array}{c}\text { N-doped porous } \\
\text { C }\end{array}$ & $\begin{array}{l}\text { 1.Synthesis of ZIF } \\
\left(\mathbf{7 5 0 - 9 5 0}{ }^{\circ} \mathbf{C}, \mathbf{1 0}\right. \\
\text { h) } \\
\text { 2.Pyrolysis }\end{array}$ & $0.05 \mathrm{M} \mathrm{H}_{2} \mathrm{SO}_{4}$ & 23.8 & - & -0.9 & $\begin{array}{l}\text { Indophenol } \\
\text { blue method }\end{array}$ & [14] \\
\hline $\mathrm{N}$-doped C foams & $\begin{array}{l}\text { 1.Ball milling } \\
(500 \mathrm{rpm}, 10 \mathrm{~h}) \\
\text { 2.Heat treatment } \\
\left(\mathbf{8 0 0 - 9 5 0}{ }^{\circ} \mathbf{C}, \mathbf{6 ~ h}\right)\end{array}$ & $0.1 \mathrm{M} \mathrm{HCl}$ & 15.7 & - & -0.2 & $\begin{array}{l}\text { Indophenol } \\
\text { blue method }\end{array}$ & [15] \\
\hline $\begin{array}{c}\text { Polymeric } \\
\text { Carbon Nitride }\end{array}$ & $\begin{array}{l}\text { 1.Heat treatment } \\
\left(550^{\circ} \mathrm{C} \text { for } 4 \mathrm{~h}\right) \\
2 . \text { Re-calcination } \\
\left(620^{\circ} \mathrm{C} \text { for } 2 \mathrm{~h}\right)\end{array}$ & $0.1 \mathrm{M} \mathrm{HCl}$ & 8.09 & - & -0.2 & $\begin{array}{l}\text { Indophenol } \\
\text { blue method }\end{array}$ & [16] \\
\hline $\mathrm{B}_{4} \mathrm{C}$ & $\begin{array}{l}\text { Commercial bulk } \\
\mathrm{B}_{4} \mathrm{C} \\
\text { (ultrasonication } 1 \\
\text { h) }\end{array}$ & $0.1 \mathrm{M} \mathrm{HCl}$ & 26.57 & - & -0.75 & $\begin{array}{l}\text { Indophenol } \\
\text { blue method }\end{array}$ & [17] \\
\hline $\mathrm{Fe}-\mathrm{N} / \mathrm{C}-\mathrm{CNTs}$ & $\begin{array}{l}\text { Heat treatment } \\
\left(\left(200-500{ }^{\circ} \mathrm{C}\right) \text { for }\right. \\
20 \mathrm{~min})\end{array}$ & $0.1 \mathrm{M} \mathrm{KOH}$ & - & 17.43 & -0.2 & $\begin{array}{c}\text { Nessler's } \\
\text { reagent }\end{array}$ & [18] \\
\hline $\mathrm{Fe}_{2} \mathrm{O}_{3}-\mathrm{CNTs}$ & $\begin{array}{l}\text { 1.Reflux }\left(100{ }^{\circ} \mathrm{C},\right. \\
3 \mathrm{~h}) \\
\text { 2.Calcination } \\
\left(350^{\circ} \mathrm{C}, 2 \mathrm{~h}\right)\end{array}$ & $2 \mathrm{M} \mathrm{KHCO}_{3}$ & - & 0.22 & $\begin{array}{l}-2.0 \mathrm{~V}(\mathrm{vs} \\
\mathrm{Ag} / \mathrm{AgCl})\end{array}$ & $\begin{array}{c}\text { Salicylic } \\
\text { acid and ICE } \\
\text { analysis }\end{array}$ & [19] \\
\hline $\begin{array}{c}30 \text { wt. } \% \mathrm{Fe}_{2} \mathrm{O}_{3}- \\
\mathrm{CNTs}\end{array}$ & $\begin{array}{l}\text { 1.Reflux }\left(120^{\circ} \mathrm{C},\right. \\
2 \mathrm{~h}) \\
\text { 2.Calcination } \\
\left(400^{\circ} \mathrm{C}, 2 \mathrm{~h}\right)\end{array}$ & $0.5 \mathrm{M} \mathrm{KOH}$ & - & 0.649 & $\begin{array}{l}-2.0 \mathrm{~V}(\mathrm{vs} . \\
\mathrm{Ag} / \mathrm{AgCl})\end{array}$ & $\begin{array}{l}\text { Salicylate } \\
\text { method }\end{array}$ & [20] \\
\hline FePc/O-MWCNT & $\begin{array}{l}\text { Room temperature } \\
\text { stirring }(20 \mathrm{~h})\end{array}$ & $0.1 \mathrm{M} \mathrm{HCl}$ & 36 & - & -0.3 & $\begin{array}{l}\text { Indophenol } \\
\text { blue method }\end{array}$ & [21] \\
\hline $\mathrm{Pd}_{0.2} \mathrm{Cu}_{0.8} / \mathrm{rGO}$ & $\begin{array}{l}\text { Co-reduction of } \\
\text { GO and metal } \\
\text { precursors }\end{array}$ & $0.1 \mathrm{M} \mathrm{KOH}$ & 2.80 & - & -0.2 & $\begin{array}{c}\text { Nessler's } \\
\text { reagent }\end{array}$ & [22] \\
\hline $\mathrm{Au} / \mathrm{CeO}_{\mathrm{x}}-\mathrm{RGO}$ & $\begin{array}{l}1 . \text { Hummer's } \\
\text { method } \\
\text { 2.Magnetic } \\
\text { stirring }\end{array}$ & $0.1 \mathrm{M} \mathrm{HCl}$ & 8.3 & - & -0.2 & $\begin{array}{l}\text { Indophenol } \\
\text { blue method }\end{array}$ & [23] \\
\hline $\mathrm{FePc} / \mathrm{C}$ & $\begin{array}{l}1 . \text { Pyrolysis } \quad(800 \\
\left.{ }^{\circ} \mathrm{C}, 1 \mathrm{~h}\right) \\
\text { 2.Annealing }(200 \\
\left.{ }^{\circ} \mathrm{C} \text { for } 2 \mathrm{~h}\right)\end{array}$ & $0.1 \mathrm{M} \mathrm{Na}_{2} \mathrm{SO}_{4}$ & 10.25 & - & -0.3 & $\begin{array}{l}\text { Indophenol } \\
\text { blue method }\end{array}$ & [24] \\
\hline
\end{tabular}

catalysts for NRR 
$\mathbf{N}$ : nitrogen; $\mathbf{C}$ : carbon; $\mathbf{B}_{\mathbf{4}} \mathbf{C}$ : boron carbide; Fe-N/C-CNT: Iron-nitrogen/carbon-carbon nanotube catalyst; CNT: carbon nanotube; FePc/O-MWCNT: Iron phthalocyanine on oxidized multiwalled carbon nanotube; PdCu/rGO: Palladium-copper amorphous nanocluster anchored on reduced graphene oxide; Au/CeO-RGO: Cerium oxide-induced amorphization of gold $(\mathrm{Au})$ nanoparticles anchored on reduced graphite oxide; FePc/C: iron phthalocyanine on nano/macroporous carbon. 


\section{REFERENCES:}

[1] S.-J. Lee, S.-I. Pyun, S.-K. Lee, S.-J. L. Kang, Isr. J. Chem. 2008, 48, 215-228.

[2] Y. Jiang, Y. Lu, X. Lv, D. Han, Q. Zhang, L. Niu, W. Chen, ACS Catal. 2013, 3, 1263-1271.

[3] R. Cao, R. Thapa, H. Kim, X. Xu, M. Gyu Kim, Q. Li, N. Park, M. Liu, J. Cho, Nat. Commun. 2013, 4, 2076.

[4] S. Zhang, H. Zhang, X. Hua, S. Chen, J. Mater. Chem. A 2015, 3, 10013-10019.

[5] J. Yang, F. Toshimitsu, Z. Yang, T. Fujigaya, N. Nakashima, J. Mater. Chem. A 2017, 5, $1184-1191$.

[6] G. Dong, M. Huang, L. Guan, Phys. Chem. Chem. Phys. 2012, 14, 2557-2559.

[7] I. S. Kwon, I. H. Kwak, J. Y. Kim, H. G. Abbas, T. T. Debela, J. Seo, M. K. Cho, J.-P. Ahn, J. Park, H. S. Kang, Nanoscale 2019, 11, 14266-14275.

[8] X. Yan, X. Xu, Z. Zhong, J. Liu, X. Tian, L. Kang, J. Yao, Electrochim. Acta 2018, 281, 562570.

[9] N. Komba, G. Zhang, Q. Wei, X. Yang, J. Prakash, R. Chenitz, F. Rosei, S. Sun, Int. J. Hydrogen Energy 2019, 44, 18103-18114.

[10] C. Zhang, R. Hao, H. Yin, F. Liu, Y. Hou, Nanoscale 2012, 4, 7326-7329.

[11] Z. Zhang, M. Dou, J. Ji, F. Wang, Nano Energy 2017, 34, 338-343.

[12] D. Liu, Y.-T. Long, ACS Appl. Mater. Interfaces 2015, 7, 24063-24068.

[13] X. Yan, X. Xu, Q. Liu, J. Guo, L. Kang, J. Yao, J. Power Sources 2018, 389, 260-266.

[14] Y. Liu, Y. Su, X. Quan, X. Fan, S. Chen, H. Yu, H. Zhao, Y. Zhang, J. Zhao, ACS Catal. 2018, $8,1186-1191$.

[15] X. Yang, K. Li, D. Cheng, W.-L. Pang, J. Lv, X. Chen, H.-Y. Zang, X.-L. Wu, H.-Q. Tan, Y.H. Wang, et al., J. Mater. Chem. A 2018, 6, 7762-7769.

[16] C. Lv, Y. Qian, C. Yan, Y. Ding, Y. Liu, G. Chen, G. Yu, Angew. Chemie Int. Ed. 2018, 57, $10246-10250$.

[17] W. Qiu, X.-Y. Xie, J. Qiu, W.-H. Fang, R. Liang, X. Ren, X. Ji, G. Cui, A. M. Asiri, G. Cui, et al., Nat. Commun. 2018, 9, 3485. 
[18] Y. Wang, X. Cui, J. Zhao, G. Jia, L. Gu, Q. Zhang, L. Meng, Z. Shi, L. Zheng, C. Wang, et al., ACS Catal. 2019, 9, 336-344.

[19] S. Chen, S. Perathoner, C. Ampelli, C. Mebrahtu, D. Su, G. Centi, Angew. Chemie Int. Ed. 2017, 56, 2699-2703.

[20] S. Chen, S. Perathoner, C. Ampelli, C. Mebrahtu, D. Su, G. Centi, ACS Sustain. Chem. Eng. 2017, 5, 7393-7400.

[21] F. Xu, L. Zhang, X. Ding, M. Cong, Y. Jin, L. Chen, Y. Gao, Chem. Commun. 2019, 55, $14111-14114$.

[22] M.-M. Shi, D. Bao, S.-J. Li, B.-R. Wulan, J.-M. Yan, Q. Jiang, Adv. Energy Mater. 2018, 8, 1800124.

[23] S.-J. Li, D. Bao, M.-M. Shi, B.-R. Wulan, J.-M. Yan, Q. Jiang, Adv. Mater. 2017, 29, 1700001.

[24] C. He, Z.-Y. Wu, L. Zhao, M. Ming, Y. Zhang, Y. Yi, J.-S. Hu, ACS Catal. 2019, 9, 73117317. 